\title{
Five year outcome of preterm sextuplets related to size at birth
}

\author{
N Marlow, A M Ellis, B L Roberts, R W I Cooke
}

\begin{abstract}
Preterm sextuplets were studied to examine whether growth retardation affects long term outcome. All were growing normally at 5 years. Intelligence quotients (IQ) ranged from 105-116 and motor impairment scores from $1 \cdot 0-7 \cdot 0$. No neurological or behavioural abnormalities were found. The largest sextuplet has maintained her position for growth and IQ. No relation between test scores and birth weight or perinatal variables was found in the remaining siblings.
\end{abstract}

Although severe intrauterine growth retardation is associated with a high mortality and long term morbidity, the degree to which lesser degrees of growth retardation cause problems is uncertain. One possible reason for the differences of opinion is the presence of many factors other than gestation that seem to affect fetal size at birth. ${ }^{1}$ The arbitrary use of the 10th centile of weight for gestational age to separate those thought to be at risk is associated with a high false positive rate, because normal small subjects are included with those who have failed to reach their full potential. Comparison of the performance of children who are small for gestational age with those who weighed more at birth is also attended by many confounding variables in terms of parental size and associated socioenvironmental factors.'

One way round these difficulties is to examine children from multiple pregnancies in which growth has been uneven. We report the five year neurodevelopmental outcome for sextuplets as an example of the effect of growth retardation when preconceptional and postnatal environment are the same.

\section{Patients and methods}

The pregnancy was conceived while the mother was being treated with follicle stimulating hormone and luteinising hormone (Pergonal, Serono) for primary infertility. Six fetuses were identified on the initial ultrasound scan. The mother was admitted to hospital in early pregnancy and treated with ritodrine from 14 weeks. Preterm labour at 29 weeks' gestation stopped after ritodrine was given intravenously together with a course of betamethasone. At 31 weeks' gestation an urgent caesarean section was carried out because of increasing maternal oedema and discomfort. Six teams each comprising one doctor and two nurses attended the delivery. All the sextuplets were girls, and five of them required intubation and ventilation at birth. One subsequently required no ventilation, two were extubated by 4 hours of age, and the remaining three received mechanical ventilation for 14, 20, and 66 hours respectively, for hyaline membrane disease. Their subsequent progress was unremarkable, except that one child (case 4) had a serious apnoeic attack at 56 days, which required resuscitation and a course of antibiotics. Perinatal details are shown in table 1 . The children were followed up prospectively at yearly intervals by one observer (RWIC). No serious illnesses or neurodevelopmental problems were encountered.

For the five year assessment all the siblings were examined on the same morning by observers who were unaware of the perinatal course or birth weights. The assessment comprised: a full neurological examination, ${ }^{2}$ the test of motor impairment (NM), ${ }^{3}$ the British ability scales (AME), a Rutter A(2) parental questionnaire, and measurement of height, weight, and head circumference. Seven subscales of the British ability scales were used to compute a general quotient (IQ) with visual and verbal subquotients. ${ }^{4}$ The children were 62 months old at assessment.

\section{Results}

Each child completed all parts of the test. No child had a focal neurological abnormality. Four were right handed, one was uncertain (case 5), and one left handed (case 6). Four were observed to have two or more minor neurological signs. The impairment scores ranged from $1 \cdot 0$ to $7 \cdot 0$. The median score for a group of 53 control children at 6 years of age examined by the same observer was $3 \cdot 0 .^{5}$
Department of Child Health, Liverpool Maternity Hospital

N Marlow

A M Ellis

B L Roberts

R W I Cooke

Correspondence to: Dr N Marlow,

Department of Child Health, Bristol Maternity Hospital,

Southwell Street,
Bristol BS2 8EG.

Accepted 3 November 1989

Table 1 Perinatal details of the sextuplets

\begin{tabular}{|c|c|c|c|c|c|c|c|c|}
\hline \multirow[t]{2}{*}{ Case No } & \multicolumn{2}{|c|}{ Birth weight } & \multirow{2}{*}{$\begin{array}{l}\text { Head } \\
\text { circumference }(\mathrm{cm})\end{array}$} & \multicolumn{2}{|c|}{ Apgar score } & \multirow{2}{*}{$\begin{array}{l}\text { First pH } \\
\text { analysis }\end{array}$} & \multirow{2}{*}{$\begin{array}{l}\text { No of days } \\
\text { ventilated }\end{array}$} & \multirow[t]{2}{*}{ Blood group } \\
\hline & $g$ & $S D$ score ${ }^{*}$ & & $1 \mathrm{~min}$ & $5 \mathrm{~min}$ & & & \\
\hline $\begin{array}{l}1 \\
2 \\
3 \\
4 \\
5 \\
6\end{array}$ & $\begin{array}{r}1598 \\
1340 \\
1290 \\
1230 \\
1060 \\
930\end{array}$ & $\begin{array}{l}-0.21 \\
-1.24 \\
-1.44 \\
-1.68 \\
-2.36 \\
-2.88\end{array}$ & $\begin{array}{l}28 \cdot 8 \\
28 \cdot 5 \\
27 \cdot 7 \\
27 \cdot 4 \\
26 \cdot 7 \\
26 \cdot 0\end{array}$ & $\begin{array}{l}2 \\
2 \\
5 \\
3 \\
9 \\
4\end{array}$ & $\begin{array}{l}5 \\
5 \\
9 \\
8 \\
9 \\
8\end{array}$ & $\begin{array}{l}7 \cdot 12 \\
7 \cdot 32 \\
7 \cdot 18 \\
7 \cdot 17 \\
7 \cdot 23 \\
7 \cdot 23\end{array}$ & $\begin{array}{r}4 \\
66 \\
4 \\
20 \\
14\end{array}$ & $\begin{array}{l}\mathrm{A} \\
\mathrm{O}+ \\
\mathrm{O} \\
\mathrm{O}+ \\
\mathrm{O}+ \\
\mathrm{O}\end{array}$ \\
\hline
\end{tabular}

"SD score $=$ difference from the mean for each age related measurement divided by the SD taken from normative data. $\dagger=$ similar minor blood groups but different HLA types. 
Table 2 Five year outcome measures

\begin{tabular}{|c|c|c|c|c|c|c|c|c|c|}
\hline \multirow{2}{*}{$\begin{array}{l}\text { Case } \\
\text { No }\end{array}$} & \multirow{2}{*}{$\begin{array}{l}\text { Height } \\
\text { (cm) }\end{array}$} & \multirow{2}{*}{$\begin{array}{l}\text { Weight } \\
(\mathrm{kg})\end{array}$} & \multirow{2}{*}{$\begin{array}{l}\text { Head } \\
\text { circumference } \\
(\mathrm{cm})\end{array}$} & \multicolumn{3}{|c|}{ British ability scales } & \multirow{2}{*}{$\begin{array}{l}\text { Test of } \\
\text { motor } \\
\text { impairment } \\
\text { score }\end{array}$} & \multirow{2}{*}{$\begin{array}{l}\text { No of } \\
\text { minor } \\
\text { neurological } \\
\text { signs }\end{array}$} & \multirow{2}{*}{$\begin{array}{l}\text { Rutter } \\
\text { behavioural } \\
\text { score }\end{array}$} \\
\hline & & & & General IQ & Visual IQ & Verbal IQ & & & \\
\hline $\begin{array}{l}1 \\
2 \\
3 \\
4 \\
5 \\
6\end{array}$ & $\begin{array}{l}124.0 \\
111.5 \\
117.0 \\
111.5 \\
112.5 \\
114.5\end{array}$ & $\begin{array}{l}24 \cdot 6 \\
17 \cdot 6 \\
18 \cdot 5 \\
17 \cdot 6 \\
16 \cdot 0 \\
17 \cdot 2\end{array}$ & $\begin{array}{l}52 \\
50 \\
50 \\
50 \\
48 \\
49\end{array}$ & $\begin{array}{l}116 \\
106 \\
108 \\
110 \\
105 \\
110\end{array}$ & $\begin{array}{l}117 \\
110 \\
100 \\
103 \\
106 \\
107\end{array}$ & $\begin{array}{l}116 \\
106 \\
108 \\
110 \\
105 \\
109\end{array}$ & $\begin{array}{l}3 \cdot 5 \\
1 \cdot 0 \\
7 \cdot 0 \\
6 \cdot 5 \\
6 \cdot 0 \\
2 \cdot 0\end{array}$ & $\begin{array}{l}0 \\
3 \\
3 \\
3 \\
0 \\
2\end{array}$ & $\begin{array}{r}4 \\
18 \\
17 \\
11 \\
10 \\
14\end{array}$ \\
\hline
\end{tabular}

IQ scores ranged from 105 to 116 . One child (case 2) had a high verbal compared with visual score, and two (cases 3 and 4) had low visual scores. Both of these also had high impairment scores (6.5 and $7 \cdot 0$, respectively). The remaining results are shown in table 2 .

The birth weights fell into three groups, and the occipitofrontal head circumference for each child corresponded to the birth weight. Two were more than $2 \mathrm{SD}$ below the mean for 31 weeks' gestation, and three were between 1 and 2 SD. All were growing satisfactorily at 5 years: height SD scores ranged from +0.66 to $+3 \cdot 4$. The child with the least deviation of birth weight from the mean (case 1) has maintained her position in terms of growth and IQ. She has blood group A. The remainder were blood group $\mathrm{O}$, three with identical minor blood groupings but different HLA types. Among these five no relationship between birth weight and IQ, subscale, or impairment scores could be identified. No perinatal factor was able to predict the order of any outcome variable at 5 years.

\section{Discussion}

Many preconceptional and environmental factors determine birth weight, including maternal age, size, parity, and socioeconomic class. Among social factors smoking is perhaps the most important. ${ }^{1}$ Such complex influences make the interpretation of studies of the influence of birth weight for gestational age on neurodevelopmental outcome difficult to interpret, as most do not control for such confounding genetic and environmental factors and none are prospective. Although there is evidence of disadvantage among small for gestational age children born at full term, those studies that attempt to study the outcome of preterm small for gestational age children are generally inconclusive. ${ }^{6}$

The chance to study a sibship of six who were exposed to the same preconceptional and rearing environments was therefore of great interest. None the less, even siblings in this sextuplet group have differing genetic influences, as shown by the differences in blood group and HLA typing. The birth weights, which presumably reflect the degree to which each child achieved its growth potential, fall into three groups. The heaviest child at birth, with a different $\mathrm{ABO}$ group from her siblings, has maintained her position in terms of growth and five year IQ test scores. Among the three sextuplets whose birth weights fell between -1.0 and $-2 \cdot 0 \mathrm{SD}$ below the mean there are no clear differences in growth or test scores compared with the two whose birth weights were more than 2 SD below the mean. Impairment scores, neurological signs, and behavioural scores were similarly unrelated to perinatal variables.

A similar range of tests was used to study the six year performance of 53 children with birth weights of less than $1251 \mathrm{~g} .{ }^{5}$ Within this group no influence of birth weight or gestational age was found, but multiple regression analysis associated low five minute Apgar scores, neonatal neurological abnormality, and neonatal septicaemia, with poor impairment scores. None of the sextuplets had any neonatal neurological abnormality and all had normal cerebral ultrasound scans. Their test scores follow a similar pattern to our previous study, with normal IQs and a wide range of motor impairment scores.

In these sextuplets, therefore, though the largest at birth has maintained her position in terms of growth and IQ, no effect of birth weight or perinatal events was found among the remainder.

1 Brooke OG, Anderson HR, Bland JM, Peacock JL, Stewart $\mathrm{CM}$. Effects on birthweight of smoking, alcohol, caffeine, socioeconomic factors and psychosocial stress. Br Med $\mathscr{f}$ socioeconomic factors

2 Touwen BCL. Examination of the child with minor neurological dysfunction. Clinics in Developmental Medicine No 71 . dysfunction. Clinics in
London: SIMP, 1967.

3 Stott DH, Moyes FA, Henderson SE. Test of motor impairment (Henderson revision). Guelph: Brook Educational, 1984

4 Elliot CD. The British ability scales. Windsor: NFER Nelson, 1983.

5 Marlow N, Roberts BL, Cooke RWI. Motor skills in extremely low birthweight children at the age of 6 years. Arch Dis Child 1989;64:839-47.

6 Allen MC. Developmental outcome and follow up of the small for gestational age infant. Semin Perinatol 1982: 123-56. 